"Prevention and Management of Diabetes-Related Eye Disease" is published by the American Diabetes Association, 2451 Crystal Drive, Arlington, VA 22202. Contact: 1-800-DIABETES, professional. diabetes.org.

The opinions expressed are those of the authors and do not necessarily reflect those of Genentech or the American Diabetes Association. The content was developed by the authors and does not represent the policy or position of the American Diabetes Association, any of its boards or committees, or any of its journals or their editors or editorial boards.

C 2019 by American Diabetes Association. All rights reserved. None of the contents may be reproduced without the written permission of the American Diabetes Association.

To request permission to reuse or reproduce any portion of this publication, please contact permissions@diabetes.org.

\section{Dualities of Interest}

T.W.G. has received research support from Zebra Biologics and consulting fees from Novo Nordisk.

C.C. W. has received research support from Adverum, Allergan, Apellis, Clearside,

Genentech, Roche, Neurotech, Novartis, Opthea, Regeneron, Regenxbio, Samsung, and Santen; is a consultant for Adverum, Alimera Sciences, Allegro, Allergan, Apellis, Bayer, Clearside, EyePoint, Genentech, Kodiak, Novartis, Regeneron, Regenxbio, and Roche; and is a speaker for Regeneron.

B.A.C. has been a speaker for Novo Nordisk and served on an advisory board for Regeneron.

No other potential conflicts of interest relevant to this compendium were reported.

\section{Acknowledgments}

Editorial and project management services were provided by Debbie Kendall of Kendall Editorial in Richmond, VA.

\section{Author Contributions}

All authors researched and wrote their respective sections. Lead author T.W.G. reviewed all content and is the guarantor of this work.

\section{About the Cover}

Proliferative diabetic retinopathy showing neovascularization and scar tissue, a condition that needs immediate surgery. Credit: Visuals Unlimited, Inc. / Chris Barry / Getty Images

\section{TABLE OF CONTENTS}

1 | Introduction

Thomas W. Gardner, MD, MS, University of Michigan Medical

School, Kellogg Eye Center, Ann Arbor, MI

3 | Optimizing Medical Management for Patients with Diabetes-Related Retinopathy

Jennifer A. Wyckoff, MD, and Anjali R. Shah, MD, University of Michigan Medical School, Kellogg Eye Center, Ann Arbor, MI

6 I Cataracts and Their Treatment in People with Diabetes

Jill E. Bixler, MD, University of Michigan Medical School, Kellogg Eye Center, Ann Arbor, MI

11 | Management of Diabetes-Related Retinopathy Charles C. Wykoff, MD, PhD, Retina Consultants of Houston; Blanton Eye Institute; Houston Methodist Institute for Academic Medicine, Houston Methodist Research Institute; and Weill Cornell Medical College, Houston Methodist Hospital, Houston, TX

16 | Emotional Support of People with Diabetes-Related Retinopathy Blake A. Cooper, MD, and Ravi S.J. Singh, MD, Retina Associates, PA, Shawnee Mission, KS

21 | Summary and Conclusion Thomas W. Gardner, MD, MS, University of Michigan Medical School, Kellogg Eye Center, Ann Arbor, MI

22 | References 